\title{
Ultimate Capacity of Reinforced Concrete Rectangular Members Subjected to Combined Actions
}

\author{
Pu Wang ${ }^{1, a}$, Quansen Wang ${ }^{1, b}$, Zhen Huang ${ }^{1, c^{*}}$ \\ ${ }^{1}$ School of Naval Architecture, Ocean and Civil Engineering, Shanghai Jiaotong University, \\ Shanghai, 200240, P.R. China \\ awangpu@sjtu.edu.cn \\ b397971211@qq.com \\ czhenhuang@sjtu.edu.cn
}

Keywords: Ultimate capacity; Axial force; Bending; Shear force; Torsion; Rectangular section.

Abstract. Rectangular reinforced concrete members are widely used in building structures and bridge structures. The failures of these members usually occur under the combined loading actions of axial force, bending, shear and torsion. In this paper, a calculate model is established by determining the shape of warped failure surface and reasonably assuming the stress distribution on the failure surface. Then through the comparison of calculation results and experiment, the validation is verified for the calculation model of ultimate capacity of reinforced concrete members with rectangular section under combined actions.

\section{Introduction}

Reinforced concrete (RC) members in hazards are usually subjected to different combinations of axial loads, bending moment, shear force and torsion. The behaviors of these RC members are very complex and difficult to be expressed with a unified failure model. The expressions of failure strength are basically statistical. Therefore it is important to research the failure mechanism of RC members under combined actions, and establish a theoretical.

Based on theoretical deduction and experimental date, abundant fruits ${ }^{[1,2]}$ were reaped on RC members subject to single loading or two and three combination of the four loadings. However, researches are quite rare for $\mathrm{RC}$ members subjected to four loading combination of axial force, bending, shear and torsion.

The co-author of the paper proposed two theoretical models ${ }^{[3,4]}$ for box-section members under combined actions in 2006 and 2007. In this paper, a theoretical calculation model is proposed for the ultimate capacity of RC members with a rectangular section.

\section{Basic assumption}

The calculation model is established based on the bellowing assumptions.

1. The concrete in the compressive zone achieve its compressive strength. The deformation of the member assumes to observe the assumptions of Euler-Bernoulli beam theory. This means the calculation model is more suitable the members with a larger ratio of shear span to effective depth.

2. The stresses of stirrups assume to achieve to their yield strength when across the warped failure surface.

3. The dowel action of rebar isn't considered in the model.

4. The influence of loading history is not considered in the model.

\section{Expression of the calculation model}

The procedure to establish the calculation model for reinforced concrete members under combined actions is based on the limit equilibrium method. In order to establish the model, the parameters for the warped failure surface should be firstly determined. As shown in the fig 1, the warped failure surface can be described by one depth of compressive zone $\mathrm{x}$ and three failure crack angles $\theta_{i}$. 


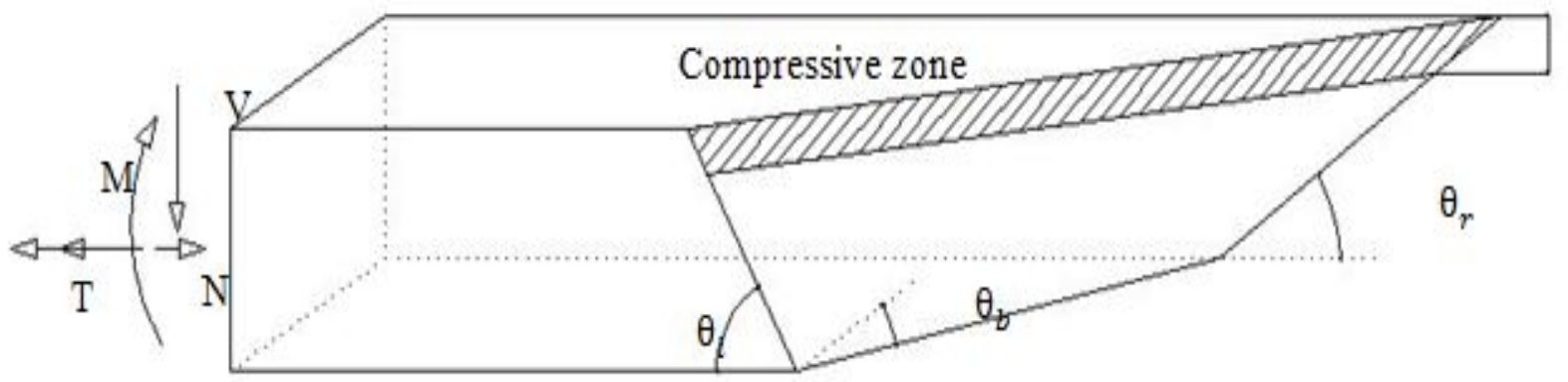

Fig.1 The warped failure surface

The depth of compressive zone $\mathrm{x}$ can be obtained from the Eq.1 and Eq.2 based on Euler-Bernoulli beam theory.

$$
\begin{aligned}
& N=\sigma_{g} A_{g}-f_{g}^{\prime} A_{g}^{\prime}-f_{g} b x \\
& \sigma_{s}=E_{s} \varepsilon_{\mathrm{cu}}\left(\frac{\mathrm{h}_{\mathrm{g}}}{\mathrm{x}}-1\right)
\end{aligned}
$$

The section can be divided into 4 zones as shown in the Fig. 2. In the limit state, the stress state of concrete has already become into the plastic stress state. Therefore, the stress of the points where first cracks appear in each zone can be expressed by Eq.3. $w_{t}$ is the plastic torque modulus of section.

$$
\begin{array}{ll}
\sigma_{l}=\frac{N}{b h}+\frac{24 M}{7 b h^{2}}, & \tau_{l}=\frac{T}{W_{t}}+\frac{V}{b h} \\
\sigma_{r}=\frac{N}{b h}+\frac{24 M}{7 b h^{2}}, & \tau_{r}=\frac{T}{W_{t}}-\frac{V}{b h} \\
\sigma_{b}=\frac{N}{b h}+\frac{24 M}{7 b h^{2}}, & \tau_{b}=\frac{T}{W_{t}}
\end{array}
$$

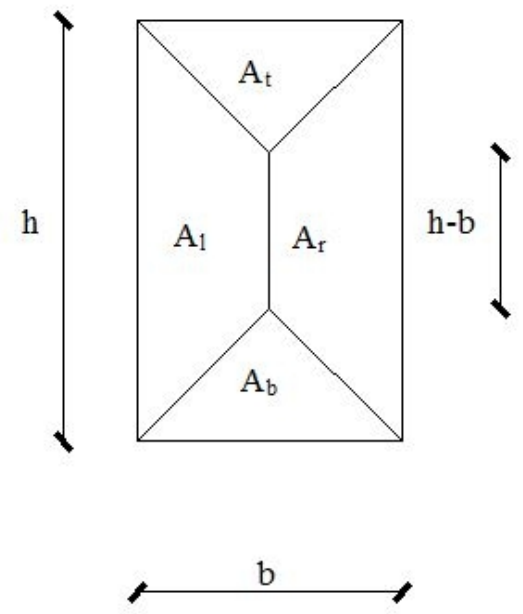

Fig.2 Section division

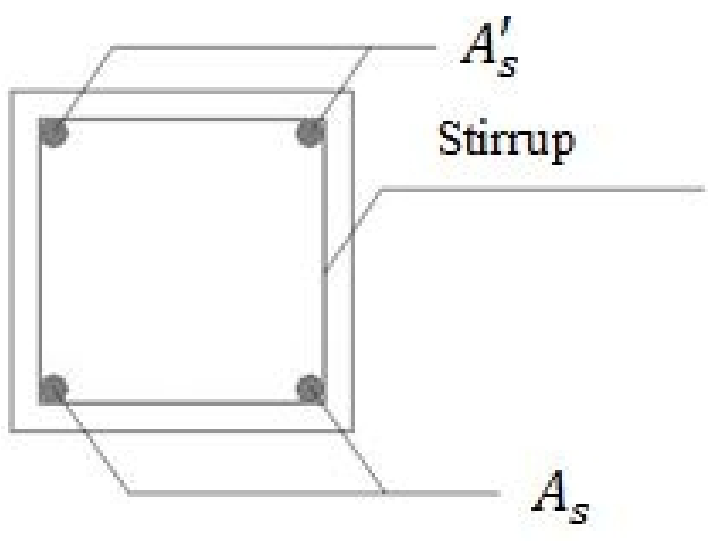

Fig.3 reinforcement drawing

Eq.4 can be established from the force equilibrium in the left zone. $F_{l}$ is the shear force undertaken by the concrete in the left zone. $A_{l}$ is the area of left zone. $F_{l}$ can be calculated using concrete shear strength $\tau_{v}$ under the normal stress. Eq.5 presents the relationship between $n_{i}$ and 
$\cot \theta_{\bar{i}}$. From Eq.4 and Eq.5, the failure crack angle $\theta_{l}$ can be obtained. Similarly the other two failure crack angles can be calculated.

$$
\begin{aligned}
& \frac{T}{2 A_{c a r}} h_{c o r}+\frac{V}{2}=n_{l} A_{s w 1} f_{y w}+F_{l} \\
& \mathrm{n}_{\mathrm{i}}=\frac{\mathrm{h}_{c o r} \cot \theta_{\mathrm{i}}}{\varepsilon}, \mathrm{i}=1, \mathrm{r}_{\mathrm{r}} \mathrm{b}
\end{aligned}
$$

From the bending moment equilibrium of the compression zone's center, Eq. 6 can be established.

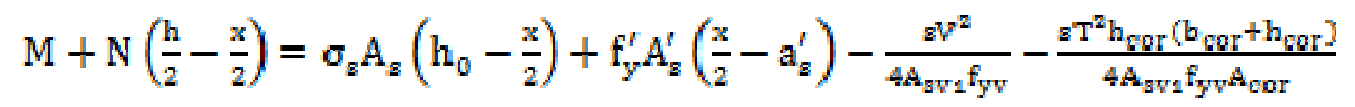

Substituting Eq.4 and Eq.5 into Eq.6, Eq.7 is expressed as the following.

$$
\frac{\mathrm{N}}{\mathrm{N}_{0}}+\frac{\mathrm{M}}{\mathrm{M}_{0}}+\frac{\mathrm{V}^{\mathrm{s}}}{\mathrm{V}_{0}^{\mathrm{s}}}+\frac{\left(\mathrm{T}-\mathrm{T}_{\mathrm{Q}}\right)^{\mathrm{2}}}{\mathrm{T}_{0}^{\mathrm{n}}}=1
$$

While,

$$
\begin{aligned}
& \mathrm{N}_{0}=\left[\sigma_{z} A_{z}\left(h_{0}-\frac{x}{2}\right)+f_{y}^{\prime} A_{z}^{\prime}\left(\frac{x}{2}-a_{z}^{\prime}\right)\right] /\left(\frac{h}{2}-\frac{x}{2}\right) \\
& M_{0}=\sigma_{s} A_{s}\left(h_{0}-\frac{x}{2}\right)+f_{y}^{z} A_{s}^{\prime}\left(\frac{x}{2}-a_{s}^{\prime}\right) \\
& v_{0}^{2}=4 A_{\mathrm{zv} 1} f_{\mathrm{yv}}\left[\sigma_{z} A_{z}\left(h_{0}-\frac{x}{2}\right)+f_{y}^{\prime} A_{z}^{\prime}\left(\frac{x}{2}-a_{z}^{\prime}\right)\right] / s \\
& \mathrm{~T}_{0}^{2}=4 \mathrm{~A}_{\mathrm{zv} 1} \mathrm{f}_{\mathrm{yw}} \mathrm{A}_{\mathrm{cor}}^{2}\left[\sigma_{\mathrm{z}} \mathrm{A}_{\mathrm{z}}\left(\mathrm{h}_{0}-\frac{\mathrm{x}}{2}\right)+\mathrm{f}_{\mathrm{y}}^{\prime} \mathrm{A}_{\mathrm{z}}^{\prime}\left(\frac{\mathrm{x}}{2}-\mathrm{a}_{\mathrm{z}}^{\prime}\right)\right] /\left[\mathrm{sh}_{\mathrm{cor}}\left(\mathrm{b}_{\mathrm{cor}}+\mathrm{h}_{\mathrm{cor}}\right)\right] \\
& \mathrm{T}_{c}=\frac{b^{2}}{6}(3 h-b) \tau_{c}
\end{aligned}
$$

\section{Validation of the calculation model}

To verify the reliability and accuracy of the calculation model, the model results are compared with the experimental results from the reference [5]. The sections of member are $240 \mathrm{~mm} \times 240 \mathrm{~mm}$. The longitudinal steel bars are symmetrical, shown as the Fig.3. The areas of longitudinal steel bars are $A_{s}$ in the tension zone. The web reinforcements are $\varnothing 6.5 \mathrm{~mm}$, the yield strength is $281 \mathrm{Mpa} . S$ is the space of the web reinforcements. The thickness of concrete cover is $15 \mathrm{~mm}$. Other parameters and comparison are shown in the Table 1. The table shows the average value is 1.06 and the variation coefficient is $15.21 \%$. The calculation model coincides well with the experimental results. 
Table 1. Comparison bewteen experimental results and theoretical model

\begin{tabular}{lcccccccccc}
\hline $\begin{array}{l}\text { Specimen } \\
\text { Name }\end{array}$ & $\begin{array}{c}\mathrm{f}_{\mathrm{c}} \\
(\mathrm{Mpa})\end{array}$ & $\begin{array}{c}\mathrm{A}_{\mathrm{s}} \\
\left(\mathrm{mm}^{2}\right)\end{array}$ & $\begin{array}{c}\mathrm{fy} \\
(\mathrm{Mpa})\end{array}$ & $\begin{array}{c}\mathrm{S} \\
(\mathrm{mm})\end{array}$ & $\begin{array}{c}\mathrm{N}_{\exp } \\
(\mathrm{kN})\end{array}$ & $\begin{array}{c}\mathrm{M}_{\exp } \\
(\mathrm{kN} \cdot \mathrm{m})\end{array}$ & $\begin{array}{c}\mathrm{V}_{\exp } \\
(\mathrm{kN} \cdot \mathrm{m})\end{array}$ & $\begin{array}{c}\mathrm{T}_{\exp } \\
(\mathrm{kN} \cdot \mathrm{m})\end{array}$ & $\begin{array}{c}\mathrm{T}_{\text {cal }} \\
(\mathrm{kN} \cdot \mathrm{m})\end{array}$ & $\begin{array}{c}\mathrm{T}_{\text {cal }} / \\
\mathrm{T}_{\text {exp }}\end{array}$ \\
\hline MV 4-3-2 & 18.3 & 628 & 413 & 70 & 457.5 & 33.1 & 60.11 & 22.84 & 24.57 & 0.99 \\
MV 5-3-2 & 18.3 & 628 & 413 & 70 & 571.88 & 31.67 & 57.93 & 23.75 & 24.55 & 0.96 \\
MV 6-3-1 & 18.3 & 628 & 413 & 70 & 686.25 & 43.64 & 80 & 24 & 17.14 & 1.09 \\
MV 3-3-2b & 18.3 & 628 & 413 & 200 & 343.13 & 23.23 & 42.4 & 16.96 & 15.43 & 1.02 \\
MV 3-3-2 & 25.7 & 628 & 413 & 70 & 481.88 & 32.33 & 59 & 23.6 & 26.89 & 0.92 \\
MV 3-2-2 & 25.7 & 628 & 413 & 70 & 481.88 & 25.99 & 47.3 & 23.65 & 28.98 & 0.96 \\
MV 4-2-2 & 25.7 & 628 & 413 & 70 & 627.5 & 29.23 & 53.2 & 26.6 & 29.86 & 0.71 \\
MV 3-5-1 & 25.7 & 763 & 418 & 70 & 481.88 & 55.91 & 102.5 & 18.45 & 19.52 & 1.13 \\
MV3-2-2b & 25.7 & 628 & 413 & 70 & 481.88 & 24.77 & 45.19 & 25.76 & 29.35 & 0.77 \\
MV 4-2-3 & 25.7 & 628 & 413 & 70 & 627.5 & 21.22 & 38.5 & 26.95 & 32.13 & 1.12 \\
MV 3-2-3 & 25.7 & 628 & 413 & 70 & 481.88 & 18.21 & 33 & 26.4 & 31.19 & 1.03 \\
MV 4-2-ul & 25.7 & 628 & 413 & 70 & 627.5 & 24.78 & 0 & 28 & 31.97 & 0.64 \\
MV 4-3-2m & 20.2 & 628 & 413 & 70 & 505 & 36.65 & 49.48 & 19.79 & 25.35 & 0.99 \\
MV 5-4-2 & 20.2 & 628 & 413 & 70 & 631.25 & 51.78 & 66.76 & 25.37 & 19.01 & 0.94 \\
Average & & & & & & & & & 1.06 & \\
Standard deviation & & & & & & & & 0.16 & \\
Variation coefficients & & & & & & & & & & \\
\hline
\end{tabular}

\section{Conclusion}

The paper presents the expression of a theoretical model for $\mathrm{RC}$ members with rectangular section under combined actions. Then the paper verifies the model through the comparison with the experiment. The good coincidence shows the validation of the model. Due to the rareness and discreteness of experimental data of RC members under combined forces, large amount of experimental data are still needed for further researches.

\section{Acknowledgement}

The authors acknowledge the National Natural Science Foundation of China for its financial support to this research project (No. 51178265).

\section{References}

[1] Vecchio F J, "Disturbed stress field model for reinforced concrete: implementation" [J]. Journal of Structural Engineering, 127 (1): 12-20.

[2] Thomas T.C.Hsu, "Toward a unified nomenclature for reinforced-concrete theory." [J] ASCE Journal of Structural Engineering, 275-283.

[3] Huang Zhen, Liu Xila, "Unified approach for analysis of box-section members under combined actions.”[J]ASCE Journal of Bridge Engineering, Vol.12, No.4:494-499.

[4] Huang Zhen, Liu Xila, "Modified Skew Bending Model for Segmental Bridge with Unbonded Tendons," [J] ASCE Journal of Bridge Eng., Vol.11, No.1:59-63.

[5] Jiakang Zhao, Liande Zhang, Yunting Wei, "Torsional strength of RC members subjected to compression, bending, shear and torsion." China Civil Engineering Journal, Vol.26, No.1 (1993) (In Chinese) 